\title{
Inflation targeting: An indirect approach to assess the direct impact
}

\author{
Taner M. Yigit* \\ Bilkent University, Department of Economics, FEASS, 06800 Ankara, Turkey
}

JEL classification:

E52

E31

$\mathrm{C} 22$

Keywords:

Inflation targeting

Long memory persistence

Heterogeneous expectations

Aggregation

\begin{abstract}
A B S T R A C T
It is quite difficult to assess the benefits of inflation targeting (IT) since its immediate effect will be on inflation expectations, an unobserved variable. Due to lack of comprehensive data on inflation expectations, most studies so far concentrated on the impact of IT either on observable variables like output, unemployment, and inflation or compared post-IT surveys of IT countries with nonIT countries. In our study, we focus on a yet unanswered question, i.e., how the expectations change with the adoption of IT. We suggest that heterogeneous inflation expectations lead to long memory in actual inflation, and IT, if successful, should decrease this persistence by concentrating the public's expectations toward the announced target. Empirical results confirm our hypothesis with a reduction in inflation memory after the adoption of IT in almost all eight developed countries in our sample.
\end{abstract}

() 2010 Elsevier Ltd. All rights reserved.

\section{Introduction}

Since its first adoption by the Central Bank of New Zealand, inflation targeting (hereafter IT) has proved to be a popular policy option among central banks. Along with the policy comparisons, a plethora of theoretical and empirical literature ${ }^{1}$ appeared on the relative performance of IT. Most of the issues revolved around its impact on observable policy variables like inflation (Siklos, 1999; Neumann and von Hagen, 2002; Petursson, 2004) and output (Bernanke et al., 1999; Levin et al., 2004). However, an important measure of success for any monetary authority in reaching their

\footnotetext{
* Tel.: +90 (312) 290 1643; fax: +90 (312) 2665140.

E-mail address: tyigit@bilkent.edu.tr

1 Leiderman and Svensson (1995), Bernanke and Mishkin (1997), Bernanke et al. (1999), Siklos (1999), Mishkin and SchmidtHebbel (2001), Amato and Gerlach (2002), Johnson (2002, 2003).
} 
ultimate goals depends on the extent to which the expectations of the public are reshaped by the announced or implemented policy (Woodford, 2004). The difficulty in observing the inflation expectations though, led some researchers to utilize consensus surveys for testing the effectiveness of IT (Johnson, 2002, 2003; Levin et al., 2004).

Surveys unfortunately provide very little information on the conditions prior to the adoption of IT. Therefore, the studies using them concentrate more on the comparison of inflation expectations of targeters versus the non-targeters in order to evaluate IT's effectiveness. However, the true assessment of how adoption of IT changes inflation expectations requires the comparison of expectations before and after the switch to IT. In this study, we offer an indirect methodology that enables one to make that very comparison by deriving inference on inflation expectations from long run dynamics of the inflation process. Two useful byproducts of our analysis are (1) offering an alternative explanation as to why long memory exists in inflation, and (2) providing an alternative theoretical explanation to the empirical evidence of the decline in inflation persistence for inflation targeting countries (Siklos, 1999; Kuttner and Posen, 2001; Petursson, 2004; Levin et al., 2004).

The basis of our theory is to indirectly examine the distribution of inflation expectations through an analysis of the time series properties of inflation. As an initial step, we show how the heterogeneity in inflation expectations (in a discretionary policy environment) leads to increased persistence in actual inflation. If an IT monetary policy succeeds in decreasing this heterogeneity, inflation persistence will decline as well. Therefore, testing for and observing the reduction in persistence after the switch to IT will constitute the indirect evidence of IT's effectiveness in focusing the expectations toward the announced target. Our theoretical and empirical findings will also offer a new explanation as to why there exists a long memory process ${ }^{2}$ (fractional integration) in inflation. Observing the reduction of inflation inertia after the switch to IT, we deduce that the aggregation of heterogeneous inflation expectations is the real culprit behind the long memory in inflation. In addition, our theory offers a possible theoretical justification to the empirical evidence of persistence declines in inflation after IT.

For any monetary policy to be effective, it is important that the public understands the central bank's actions and forms their expectations in accordance with these actions. The inflation targeting rule facilitates the public's understanding of the monetary policy and thus has an effect on the expectations of the public. According to Woodford (2004) and Faust and Henderson (2004), such a commitment to an announced target helps the public to form anchored expectations for the policy outcome. Siklos (1999), Corbo et al. (2001), and Petursson (2004) examine these effects of inflation targeting using multiple countries to find that the level and fluctuations of inflation along with its persistence have all decreased after the adoption of IT. While these authors concentrate on the "observable" effects of IT, others aimed to test its effectiveness on expectations directly. Johnson (2002, 2003) and Levin et al. (2004) utilize Consensus Economic Forecasts to measure the effectiveness of IT on inflation and output. While Johnson finds IT effectiveness on the mean, variability, and forecast errors of inflation, Levin et al. shows that it holds for the sacrifice ratio as well. Our study forms a bridge between these two branches in the literature by deriving conclusions on unobservable changes such as the distribution of inflation expectations via the analysis of observable inflation persistence. In this regard, we make up for the lack of such an analysis in the literature and explain how expectations change with the adoption of IT.

As a byproduct, our analysis contributes to the literature on long memory processes. Despite substantial evidence of its relevance in many macroeconomic series, ${ }^{3}$ there have not been many papers establishing the economic origins of long memory processes in macroeconomic variables. Until

\footnotetext{
${ }^{2}$ Long memory refers to when persistence of shocks is caused by either a unit or a fractional root. Unit root or I(1) models have non-decreasing autocorrelation functions while fractionally integrated and stationary ARMA or $I(0)$ processes have hyperbolical and geometric declines, respectively. In other words, fractionally integrated models constitute a middle ground between the $I(1)$ and $I(0)$ worlds.

${ }^{3}$ Sowell (1992) and Abadir and Talmain (2002) show existence of long memory in aggregate economic activity, while Hassler and Wolters (1995), Baillie et al. (1996) analyze fractional integration in aggregate prices. Andersen and Bollerslev (1997) and Liu (2000) provide evidence of long memory in asset price volatility.
} 
recently, the most common ${ }^{4}$ explanation for fractionally integrated processes in economics has been Granger's (1980) cross-sectional aggregation ${ }^{5}$ of a large number of heterogeneous dynamic processes. Aggregation over individuals or firms has been advanced as the source of long memory in many empirical studies on aggregate economic series. Specifically regarding inflation, there have been only a few suggestions as to the source of long memory, namely aggregation in price indexes (Hassler and Wolters, 1995), aggregation of heterogeneous firm production (Abadir and Talmain, 2002), and persistence in money supply shocks (Scacciavillani, 1994). We propose instead the aggregation of heterogeneous inflation expectations as the reason behind inflation persistence. IT and its main goal of anchoring expectations (and therefore reducing their heterogeneity), provide us with a perfect lab experiment for the testing of our proposition.

Next section sets up the relation between the theoretical and the econometric framework. Section 3 describes the estimation technique and the results while the last section concludes.

\section{Setup}

In the subsections below, we formulate some conditions for inflation expectations heterogeneity to produce long memory process in inflation. One should keep in mind that the main purpose of the study is to propose a practical link between inflation persistence, inflation targeting and heterogeneous expectations. In this respect, we provide an economic theory to derive conclusions about the time series properties of inflation. It is quite possible that variations of the model below can be conceived to reach the same end goal.

\subsection{Expectations}

Earlier theoretical (Crettez and Michel, 1992; Naish, 1993) and empirical (Figlewski and Wachtel, 1981; Zarnowitz, 1985; Evans and Wachtel, 1993; Evans et al., 2001; Evans and Honkapohja, 2001) studies have shown that when information acquisition is costly, the use of adaptive expectations or adaptive learning models can be more fitting with the empirical observations. ${ }^{6}$ The convergence of these models to rational expectations equilibrium (E-stability) only helped increase their appeal and use.

Utilizing a heterogeneous version of the models in Walsh (1999), Demir and Yigit (2008), and Demertzis and Viegi (2007) with time varying gain representation (to allow for a regime switch with the adoption of IT), the inflation expectation, $\pi_{i}^{e}$, for agent $i$ and period $t+1$ is

$$
\pi_{t+1}^{i e}=\pi_{t}^{i e}+\theta_{i t}(\cdot)\left(\pi_{t}^{*}-\pi_{t}^{i e}\right)+\varepsilon_{i t}
$$

where $i=1, \ldots, N$, where $\pi_{t}^{*}$ is either the consensus forecast, $\pi_{t}^{e}$, or the announced inflation target, $\pi_{t}^{a}$, (or a weighted mixture of both as in Demertzis and Viegi, 2007) and $\theta_{i t}(\cdot)$ is a credibility function ${ }^{7}$ within the interval $[0,1]$ with the argument $\left(\pi_{t-1}-\pi_{t-1}^{*}\right) .{ }^{8}$ The aggregate inflation expectation is assumed to be the mean of the individual forecasts (i.e., $\pi_{t}^{e}=(1 / N) \sum \pi_{t}^{i e}$ ), hence they are known to the individuals after they form their expectation and can be used to update their expectation in the next period. According to this setup, as the central monetary authority fails to meet the consensus expectations or hit its announced target, the public does not update its own forecast using that outside information. Naturally, the opposite happens and $\theta_{i t}$ increases with more successful performance of the monetary authority. We also assume a New Keynesian Phillips curve formulation for inflation ${ }^{9}$

\footnotetext{
${ }^{4}$ Recently Parke (1999) showed that a sequence of shocks with stochastic magnitude and duration can lead to long memory while Liu (2000) and Diebold and Inoue (2001) demonstrated that regime-switching processes can produce series that are observationally equivalent to fractional integration.

${ }^{5}$ Chambers (1998) extends this analysis by incorporating temporal aggregation to cross-sectional aggregation. Zaffaroni (2004) broadens Granger's results by using a milder semiparametric specification.

${ }^{6}$ These authors have found that forecast errors are not only serially correlated, but are also correlated with past information.

7 One could think of the example $\theta_{i t}(\cdot)=1-1 / e^{\alpha_{i}\left(\pi_{t-1}-\pi_{t-1}^{*}\right)^{2}}$.

8 Our $\theta_{i t}$ also resembles Cukierman's (1992) definition of marginal credibility.

${ }^{9}$ Although we do not provide micro foundations for this formulation for brevity, the literature is rich with such examples.
} 


$$
\pi_{t}=\gamma g_{t}+\delta \pi_{t}^{e}+\eta_{t}
$$

where $\pi_{t}^{e}$ is the aggregate expectation of inflation level $\pi_{t}$ (formed at time $t-1$ ), $g_{t}$ represents output gap, and $\eta_{t}$ is a white noise supply shock. It can be shown that the reduced form for the individual inflation expectation follows an $\operatorname{ARMAX}(1,0)$

$$
\pi_{t+1}^{i e}=\left(1-\theta_{i t}(\cdot)-\frac{\theta_{i t}(\cdot)}{N}\right) \pi_{t}^{i e}+\theta_{i t}(\cdot) \pi_{t}^{\dagger}+\varepsilon_{i t}
$$

where $\pi_{t}^{\dagger}$ represents the inflation expectation (if no IT) with the $i$ th individual subtracted out. In this setup, the individual expectations are formed by a learning process where the individual puts more weight on the consensus inflation or the IT announcement as these values are closer to the realized inflation rate. With a more successful inflation management by the central bank (a decline in the mean and variance of $\pi_{t-1}-\pi_{t-1}^{*}$ ), the mean and the variance of the autoregressive parameter of individual expectations decline and the emphasis shifts toward $\pi_{t}^{\dagger} .10$

\subsection{Long memory}

Long memory models are generally used for series in which the order of integration is a fraction and the differencing operator, $d$, in the lag polynomial, $(1-L)^{d}$, is used to transform them into stationary series. After being introduced into the economics literature by Granger (1980), a large number of studies found evidence of its existence in many macroeconomic series. Granger showed that crosssectional aggregation of a large number of heterogeneous dynamic processes could display time series properties that are neither unit root nor ARMA stationary. In these models the autocorrelation functions display hyperbolic decay as opposed to the geometric decline of the stationary ARMA series or the non-decreasing ACF of the unit root models. In his model, Granger emphasizes that there are two necessary conditions for cross-sectional aggregation of AR(1) parameters to produce long memory in the sum: (1) heterogeneity, and (2) some series having a unit root. These necessary conditions form the second motivation behind our paper, namely, analyzing the role of the distribution of AR(1) coefficients of heterogeneous inflation expectations in the aggregation towards long memory in inflation.

We utilize two different distributions for the cross-sectional aggregation of AR(1) coefficients, the beta distribution used by Granger (1980) and a more general semi-parametric distribution by Zaffaroni (2004). Granger considers the cross-sectional aggregation of a large number of heterogeneous AR(1) processes

$$
x_{i t}=\alpha_{i} x_{i t-1}+\varepsilon_{i t}
$$

where $i=1, \ldots, N, \varepsilon_{i t}$ is white noise, $E\left(\varepsilon_{i t}, \varepsilon_{j t}\right)=0$, and $E\left(\alpha_{i}, \varepsilon_{j t}\right)=0$ for all $i, j, t$. When (square root of) $\alpha_{i}$ has the beta distribution ${ }^{11}$

$$
f(\alpha)=\frac{2}{B(p, q)} \alpha^{2 p-1}\left(1-\alpha^{2}\right)^{q-1} \text { for } 0 \leq \alpha \leq 1
$$

where $B(p, q)$ is the beta function and $N$ gets large, the aggregate series $x_{t}=\sum_{i=1}^{N} x_{i t}$ will exhibit long memory and have a fractional order of integration, $d=1-q / 2$. Granger shows that decreasing the range of $\alpha$ from above (i.e., when $\alpha$ is not allowed to be close to unity) results in the disappearance of long memory; the conclusions do not change when $\alpha$ is restricted from below. This condition demonstrates that for fractional integration, $x_{t} \sim I(d)$, heterogeneity alone is not sufficient, but the coefficients $\alpha_{i}$ should also be allowed to approach to one, i.e., the mean should be high.

\footnotetext{
${ }^{10} \mathrm{~A}$ reduction in the variance of the argument will reduce the variance of the function $\left(1-\theta_{i t}(\cdot)\right)$ since $\operatorname{var}\left(\theta_{i t}\right) \approx\left[\theta_{i t}{ }^{\prime}(\cdot)\right]^{2} \operatorname{var}\left(\pi_{t-1}-\pi_{t-1}^{*}\right)$.

11 Granger chooses the beta distribution due to its mathematical convenience and adds that the choice of the distribution does not affect the results. Beta distribution is also flexible in terms of mimicking the normal and uniform distributions for particular values of $p$ and $q$.
} 
Our analysis extends Granger's by illustrating the analytical relation of the degree of fractional differencing to the first two moments ${ }^{12}$ of the coefficient $\alpha$, namely its mean $\left(\mu_{\alpha}\right)$ and variance $\left(\sigma_{\alpha}^{2}\right)$. Mean and variance of the beta distribution are

$$
\begin{aligned}
\mu_{\alpha} & =\frac{p}{p+q}, \\
\sigma_{\alpha}^{2} & =\frac{p q}{(1+p+q)(p+q)^{2}} .
\end{aligned}
$$

Combining them with the previously mentioned fractional order of integration, $d=1-q / 2$, helps us to illustrate the relation between the order of integration and these moments. Substituting out $p$ and $q$ gives us

$$
d=\frac{3 \sigma_{\alpha}^{2}-\mu_{a} \sigma_{\alpha}^{2}-\left(1-\mu_{a}\right)^{2} \mu_{a}}{2 \sigma_{\alpha}^{2}} .
$$

The relations $\partial d / \partial \sigma_{\alpha}^{2}>0^{13}$ and $\partial d / \partial \mu_{\alpha}>0$ indicate that the degree of persistence crucially depends on the tail probability of the distribution of $\alpha$ close to one. A decrease in the variation or mean of $\alpha$ unambiguously lowers the degree of fractional differencing, and in extreme cases may eliminate it completely. A similar derivation for Zaffaroni (2004) is pushed in the Appendix I for brevity.

Drawing a parallel between the two literatures, we assume that the $x_{i t}$ and $\alpha_{i}$ of Eq. (4) correspond to the individual inflation expectations, $\pi_{t+1}^{i e}$, and the weights, $\left(1-\theta_{i t}(\cdot)-\left(\theta_{i t}(\cdot) / N\right)\right)$, in Eq. (3). Granger (1980) and Zaffaroni (2004) show that the aggregation of a pure AR(1) model results in fractionally integrated processes. Granger and Joyeux (1980) add that when $\pi_{t}^{\dagger}$ is an independent causal series (exogenous to the individual) and potentially observable to each micro component (individual) the aggregation of the heterogeneous expectations in the above (time varying) ARMAX $(1,0)$ process will be integrated of the order $d^{*}$ with $d^{*}$ being the largest of $1-d$ and $1-d+d_{\pi *}$. Thus, the aggregation of the individual expectations, $\pi_{t+1}^{i e}$, could induce a long memory process in the consensus inflation expectation, $\pi_{t+1}^{e}$, which would in turn translate into long memory in inflation via Eq. (2). ${ }^{14}$

$$
\pi_{t+1}^{e}=\frac{1}{N} \sum_{N} \pi_{t+1}^{i e} \sim I\left(d^{*}\right)=I\left(\max \left(1-d, 1-d+d_{\pi^{\dagger}}\right)\right) \rightarrow \pi_{t+1} \sim I\left(d^{*}\right) .
$$

Such a derivation offers one possible reason for the evidence of long memory in the inflation process. Other potential reasons suggested to date are persistence in money supply (Scacciavillani, 1994), aggregation of heterogeneous firm production (Abadir and Talmain, 2002), and the aggregation of individual prices into a price index (Hassler and Wolters, 1995). We distinguish our model from the others by using the adoption of inflation targeting as an experiment since it is more likely to have an impact on inflation expectation heterogeneity than the other sources of long memory listed above.

It is widely accepted that an activist central bank can create an inflationary bias because of its opportunism in surprising the public to stimulate production. As a result, persistent inflation will become ingrained in the system via the public's expectations as in Eq. (2). The adoption of inflation targeting is aimed at moderating inflation expectations by not only providing discipline in the setting of monetary policy, but also by improving the communication of policy goals and actions. A switch to inflation targeting will have three effects on the persistence parameter of inflation $d^{*}$, namely (i) eliminating $d_{\pi^{\dagger}}$ (replacing $\pi_{t}^{e}$ with $\pi_{t}^{a}$ ), (ii) decreasing the level and hence the mean of $\left(1-\theta_{i t}(\cdot)\right)$ with successful targeting, and (iii) reducing the heterogeneity of $\left(1-\theta_{i t}(\cdot)\right)$ by earning credibility via

\footnotetext{
12 It is sufficient to concentrate on just the mean and variance of $\alpha$ since the beta distribution has the convenient property of having recurrent non-central moments. Higher non-central moments contain the same information as the variance, so finding the relation of the degree of fractional differencing to higher moments would not alter our conclusions.

${ }^{13}$ Note that the mean is between 0 and 1 .

${ }^{14}$ Such a spillover requires an active monetary policy (which is the assumption of this article) to distinguish the serial correlation in the output gap from that of the inflation.
} 
Table 1

Descriptive statistics from consensus forecasts.

\begin{tabular}{|c|c|c|c|c|c|c|}
\hline & \multicolumn{3}{|c|}{ Pre-targeting } & \multicolumn{3}{|c|}{ Post-targeting } \\
\hline & Mean & Variance & Observations & Mean & Variance & Observations \\
\hline Australia & 3.57 & 0.38 & 26 & 2.67 & $0.26 *$ & 153 \\
\hline Canada & 4.84 & 0.18 & 15 & $2.14 *$ & 0.20 & 176 \\
\hline UK & 4.88 & 0.48 & 39 & $1.98^{*}$ & 0.41 & 152 \\
\hline US & 4.20 & 0.23 & 39 & $2.56^{*}$ & $0.17 *$ & 152 \\
\hline Germany & 3.38 & 0.16 & 39 & $1.85^{*}$ & 0.14 & 152 \\
\hline France & 3.18 & 0.16 & 39 & $1.65^{*}$ & 0.15 & 152 \\
\hline
\end{tabular}

Notes: The switch date for France and Germany is artificially taken as 1993Q1 and for US it is taken as 1994Q1 to control for the overall decline of world inflation. Mean is the overall average of all inflation surveys before and after the regime adoption. The variance is defined as the average of cross sectional variation in the surveys. ${ }^{*}$ Indicates difference in mean and variance terms at $95 \%$ significance level.

reducing the variance in $\left(\pi_{t-1}-\pi_{t-1}^{*}\right)$. Therefore, evidence of long memory processes present before the regime switch should disappear or be significantly reduced afterwards. In other words, in a successful IT regime, where the monetary authority will not deviate too much from its announced targets, the autoregressive parameter, $\left(1-\theta_{i t}(\cdot)\right)$, will decline and lose its heterogeneity, leading to the disappearance of long memory process. Empirical evidence of the decline in persistence would support our theory more than the other possible explanations of long memory in inflation since the adoption of inflation targeting should not have as sharp an impact on them.

\section{Estimation}

One of the main criteria of success of IT is the level of control it exerts on the public's inflation expectations. That is why the inflation targeting central banks communicate their targets clearly to the public. In return, they need to closely follow how the public responds to the target announcements in order to evaluate their effectiveness. Hence, it is quite common to observe detailed surveys of inflation expectations around the time of the switch to IT. The motivation of our study is the inadequacy of these measures of expectations prior to the adoption of IT and the resultant difficulty of measuring IT's true effect on expectations.

Table 1 displays survey information from Consensus Forecasts provided by Consensus Economics. Consensus Forecasts data consists of outlooks for over a 2-year forecast horizon by leading economists whose individual views are shown together with the average, or consensus, forecast. In other words, each month, every forecaster reports an expected rate of inflation for the end of current year and the next year. Among the countries in the dataset, only three, Australia, Canada and UK, have data both before and after the switch to IT. Examining the cross-section of inflation forecasts for these countries, one can notice the short sample length before the new regime. UK leads the pack by three years of data before IT while Canada has only one. For comparison, we also include three non-targeting countries to control for the declining inflation rates across the globe. We pick the beginning of 1993 as the break

Table 2

Descriptive statistics of monthly inflation before and after adoption of inflation targeting

\begin{tabular}{|c|c|c|c|c|c|c|}
\hline & \multicolumn{3}{|c|}{ Pre-targeting } & \multicolumn{3}{|c|}{ Post-targeting } \\
\hline & Mean & Variance & Count & Mean & Variance & Count \\
\hline Australia & 0.52 & 0.39 & 402 & 0.23 & 0.19 & 183 \\
\hline Canada & 0.44 & 0.43 & 378 & 0.16 & 0.30 & 207 \\
\hline Finland & 0.57 & 0.58 & 402 & 0.14 & 0.30 & 183 \\
\hline Israel & 2.83 & 15.85 & 375 & 0.46 & 0.67 & 210 \\
\hline New Zealand & 2.10 & 2.14 & 363 & 0.56 & 0.23 & 231 \\
\hline Spain & 0.74 & 0.74 & 420 & 0.26 & 0.41 & 165 \\
\hline Sweden & 0.55 & 0.61 & 399 & 0.12 & 0.39 & 186 \\
\hline UK & 0.60 & 0.69 & 396 & 0.16 & 0.37 & 189 \\
\hline
\end{tabular}


Table 3

Estimates for long memory parameter (fractional root) in monthly inflation using $\operatorname{ARFIMA}(p, d, q)$ specification before and after regime switch to inflation targeting.

\begin{tabular}{lcccccc}
\hline & Pre-targeting & Post-targeting & Switch date & Pre-targeting & Post-targeting & Switch date \\
\hline Australia & $0.275^{* *}(0.06)$ & $0.109^{*}(0.06)$ & $1993 \mathrm{Q} 2$ & & & \\
Canada & $-0.007(0.04)$ & $-0.118(0.08)$ & $1991 \mathrm{Q} 2$ & & & \\
Finland & $0.174^{* *}(0.06)$ & $-0.087(0.16)$ & $1993 \mathrm{Q} 2$ & & & \\
Israel & $0.379^{* *}(0.1)$ & $-0.246(0.22)$ & $1991 \mathrm{Q} 1$ & $0.374^{* *}(0.09)$ & $0.069(0.09)$ & $1997 \mathrm{Q} 1$ \\
New Zealand & $0.307^{* *}(0.07)$ & $0.132^{* *}(0.06)$ & $1990 \mathrm{Q} 1$ & & \\
Spain & $0.184^{*}(0.11)$ & $-0.185(0.09)$ & $1994 \mathrm{Q} 4$ & & & \\
Sweden & $0.313^{* *}(0.14)$ & $0.147^{* *}(0.06)$ & $1993 \mathrm{Q} 1$ & $0.446^{* *}(0.18)$ & $0.178(0.14)$ & $1995 \mathrm{Q} 1$ \\
UK & $0.158^{* *}(0.07)$ & $0.167(0.11)$ & $1992 \mathrm{Q} 4$ & $0.196^{* *}(0.04)$ & $0.252^{* *}(0.1)$ & $1997 \mathrm{Q} 1$
\end{tabular}

Notes: standard errors are reported in the parentheses. ${ }^{* *}\left({ }^{*}\right)$ Indicates $95(90) \%$ significance. Modified profile likelihood estimation on monthly inflation is used in the estimation. Seasonal factors are included in the ARFIMA $(p, d, q)$ estimation to control for seasonality. Optimal short run dynamics parameters $(p, q)$ are chosen using the BIC, but are not reported to conserve space. Estimations are done on demeaned data per the results of Choi and Zivot (2007). The number of estimated breaks, the break dates and the specific orders of $(p, q)$ are available from the author upon request.

point for the non-targeting countries (1994 for the US) ${ }^{15}$ since most of the inflation targeting countries in our sample adopted the IT regime around that date. We should warn the reader at this point that we will use the non-targeting countries only in the descriptive parts of our research since any imposed break date and the choice of non-targeting countries will be open to rightful criticism. Inspection of the results reveals that (i) the pre-targeting period data is quite short and insufficient to make any solid statements, and (ii) likely due to the first point, the survey evidence fails to provide a clear picture about how the inflation expectations are affected with the adoption of the IT regime. All of the countries, inflation targeting or not, experience statistically significant declines in their mean inflation expectations. However, the heterogeneity, measured by the cross-sectional variation of expectations among forecasters, changes significantly only in a small part of the countries, not forming a certain pattern one way or the other. Hence, survey comparisons of the pre- and post-targeting periods indicate that IT does not produce its desired impact on inflation expectations since targeting country surveys show similar patterns with those of the non-targeting countries.

The lack of clear evidence in survey data motivates our use of an indirect methodology to examine the actual inflation data in order to assess the direct impact of inflation targeting on expectations. The monthly CPI inflation data that ranges from 1961 until present is obtained from Global Financial Database. ${ }^{16}$ Table 2 displays the descriptive statistics information for the inflation level in eight IT countries. We choose these countries for the sake of consistency with the earlier literature (Bernanke et al., 1999; Ball and Sheridan, 2005; Lin and Ye, 2007). ${ }^{17}$ The monthly results resemble the picture in survey statistics. Accordingly, we resort to our indirect route, which comprises of examining the persistence level (fractional root) in the inflation process to deduce information on the changes in the expectation level and heterogeneity.

We estimate the fractional differencing parameters in the inflation process for pre- and post-IT periods in our sample countries to observe whether the decreases in the mean and heterogeneity of inflation expectations induce a decline in the fractional root $d$, as suggested by our theory. Aside from numerous empirical studies that find evidence of long memory process in the inflation series of many countries, an additional advantage of the estimation of an $\operatorname{ARFIMA}(p, d, q)$ specification is to be able to represent the long run dynamics of the inflation series by a single parameter, $d$.

As mentioned earlier, Liu (2000) and Diebold and Inoue (2001) showed that regime switches can lead to long memory processes. Motivated from this idea, recently Choi and Zivot (CZ, 2007) have

\footnotetext{
${ }^{15}$ Beginning in 1994, the FOMC began announcing changes in its policy stance, and in 1995 it began to explicitly state its target level for the federal funds rate.

${ }^{16}$ One can visit http://www.globalfinancialdata.com to obtain more information of the exact sources of each price series. Australia and New Zealand report their price series quarterly; therefore, the missing months are filled with the last available price level since expectations are formed by using them.

${ }_{17}$ Regressions have been run on other countries such as Brazil and Chile (not provided in the text but available from authors upon request), giving similar results as in other countries.
} 
Table 4

Estimates for long memory parameter (fractional root) in monthly inflation using ARFIMA-GARCH $(p, d, q, 1,1)$ specification before and after regime switch to inflation targeting

\begin{tabular}{lcccccc}
\hline & Pre-targeting & Post-targeting & Switch date & Pre-targeting & Post-targeting & Switch date \\
\hline Australia & $0.237(0.14)$ & $0.085(0.45)$ & $1993 \mathrm{Q} 2$ & & & \\
Canada & $0.103(0.06)$ & $-0.136(0.1)$ & $1991 \mathrm{Q} 2$ & & & \\
Finland & $0.451^{* *}(0.11)$ & $0.278^{* *}(0.09)$ & $1993 \mathrm{Q} 2$ & & & \\
Israel & $0.202^{* *}(0.09)$ & $-0.547^{* *}(0.18)$ & $1991 \mathrm{Q} 1$ & $0.227^{* *}(0.08)$ & $-0.475^{* *}(0.21)$ & $1997 \mathrm{Q} 1$ \\
New Zealand & $0.455^{* *}(0.02)$ & $0.174(0.11)$ & $1990 \mathrm{Q} 1$ & & \\
Spain & $0.162^{* *}(0.06)$ & $0.087(0.1)$ & $1994 \mathrm{Q} 4$ & & & \\
Sweden & $0.113^{* *}(0.05)$ & $0.515(0.53)$ & $1993 \mathrm{Q} 1$ & $0.139^{* *}(0.06)$ & $0.496(0.34)$ & $1995 \mathrm{Q} 1$ \\
UK & $0.275^{* *}(0.06)$ & $0.234(0.14)$ & $1992 \mathrm{Q} 4$ & $0.247^{* *}(0.06)$ & $0.275(0.17)$ & $1997 \mathrm{Q} 1$ \\
\hline
\end{tabular}

Notes: standard errors are reported in the parentheses. ${ }^{* *}\left({ }^{*}\right)$ Indicates 95(90)\% significance. Maximum likelihood estimation on monthly inflation is used in the estimation. Seasonality is removed from the data using TRAMO/SEATS prior to the estimation. $(k, l)$ are taken as $(1,1)$ in the estimations. Optimal short run dynamics parameters $(p, q)$ are chosen using the BIC, but are not reported to conserve space. Estimations are done on demeaned data per the results of Choi and Zivot (2007). The number of estimated breaks, the break dates and the specific orders of $(p, q)$ are available from the author upon request.

shown that structural breaks in the data can spuriously inflate the fractional root estimates. They proposed a three step method, first identifying the endogenous structural mean breaks, then demeaning the data using the differing mean estimates, and finally estimating the long memory parameter using the demeaned data. They rely on the endogenous break test of Bai and Perron (1998) for the estimation of the means. The general form of the BP (1998) methodology considers the following multiple structural break model, with $m$ breaks ( $m+1$ regimes)

$$
y_{t}=x_{t}^{\prime} \gamma_{j}+u_{t}
$$

for $t=T_{j-1}+1, \ldots, T_{j}$ and $j=1, \ldots, m+1 . y_{t}$ is the observed dependent variable at time $t ; x_{t}(q \times 1)$ is the vector of covariates (a vector of ones in our case), and $\gamma_{j}$ is the corresponding vector of coefficients, and $u_{t}$ is the disturbance term at time $t$. The break points $(T)$ are treated as unknown, and are estimated together with the unknown coefficients when $T$ observations are available. Since our estimations cover a sample of almost 50 years, we demean our data using the CZ methodology to prevent any exposure to spurious long memory estimates.

The estimations are carried out using Exact Maximum Likelihood (EML). The EML estimates both the short run ARMA parameters and the fractional root $d$ using the concentrated log-likelihood function ${ }^{18}$

$$
l_{c}(d, \phi, \theta)=-\frac{T}{2} \log (2 \pi)-\frac{T}{2}-\frac{1}{2} \log |R|-\frac{T}{2}\left(T^{-1} z^{\prime} R^{-1} z\right)
$$

where the $\operatorname{ARFIMA}(p, d, q)$ is represented as $\Phi(L)(1-L)^{d} y_{t}=\Theta(L) \varepsilon_{t}$ with $y \sim N(\mu, \Sigma), z=y-\mu$ and $R=\Sigma / \sigma_{\varepsilon}^{2}$. Estimations are carried out using ARFIMA package in OX (Ooms and Doornik, 1998). Since specifics of the method are beyond the scope of this paper we refer the reader to an excellent survey by Baillie (1996) and Ooms and Doornik (1999) for further details.

The estimation results for only $\widehat{d}$ are displayed in Table 3 while the values or orders of the ARMA parameters are not reported to conserve space. ${ }^{19}$ The seasonal effects are controlled by the addition of dummy regressors. The values in parentheses below the estimates represent their corresponding standard errors. The last three columns show alternative IT adoption dates suggested by Ball and Sheridan (2005) for Australia and Sweden and Schaechter et al. (2000) for Israel. Examination of the results shows that the fractional root declines in almost all countries with the adoption of inflation targeting. ${ }^{20}$

\footnotetext{
18 The orders of ARMA are determined using the Schwarz information criterion.

19 Specific short run dynamics of each series and the information criteria are available from the author upon request.

20 We should note that we are not running a formal test for the parameter difference in the cases of Australia and Sweden and judging the other differences from statistical significance.
} 
Table 5

Estimates for long memory parameter (fractional root) in annualized inflation using ARFIMA(p, $d, q)$ specification before and after regime switch to inflation targeting.

\begin{tabular}{lccc}
\hline & Pre-targeting & Post-targeting & Switch date \\
\hline Australia & $0.34^{* *}(0.16)$ & $0.25(0.17)$ & $1993 \mathrm{Q} 2$ \\
Canada & $0.27^{* *}(0.07)$ & $-0.01(0.15)$ & $1991 \mathrm{Q} 2$ \\
Finland & $0.31^{* *}(0.08)$ & $0.20(0.13)$ & $1993 \mathrm{Q} 2$ \\
Israel & $-0.14(0.12)$ & $0.05(0.31)$ & $1991 \mathrm{Q} 1$ \\
New Zealand & $0.40^{* *}(0.09)$ & $0.30^{*}(0.17)$ & $1990 \mathrm{Q} 1$ \\
Spain & $-0.15(0.11)$ & $-0.27^{*}(0.16)$ & $1994 \mathrm{Q} 4$ \\
Sweden & $-0.01(0.06)$ & $0.15(0.10)$ & $1993 \mathrm{Q} 1$ \\
UK & $0.16^{* *}(0.06)$ & $0.06(0.13)$ & $1992 \mathrm{Q} 4$
\end{tabular}

Notes: Standard errors are reported in the parentheses. ${ }^{* *}\left({ }^{*}\right)$ Indicates $95(90) \%$ significance. Modified profile likelihood estimation on annualized inflation is used in the estimation. Optimal short run dynamics parameters $(p, q)$ are chosen using the BIC, but are not reported to conserve space. Estimations are done on demeaned data per the results of Choi and Zivot (2007). The number of estimated breaks, the break dates and the specific orders of $(p, q)$ are available from the author upon request.

Canada shows a negative fractional root estimate, probably due to spuriously de-meaning of the data prior to the estimations. ${ }^{21}$ We also run auxiliary Monte Carlo simulations (displayed in Appendix II) to confirm that the sample size differences between the pre- and post-IT are not the reason for the disappearance of long memory process. In addition to this simulation, we check the robustness of our results to 1-year movements of the regime change in both directions since it could be argued that the break dates could be misleading due to an initial transition (credibility) period. We find that these movements in the break date do not affect our fractional root estimates at all. ${ }^{22}$ All of these findings are quite in line with the theory, showing that the long memory process that existed prior to the adoption of inflation targeting is reduced for almost all sample countries. The results corroborate that once the heterogeneity and the level in individual inflation expectations is reduced, the persistence of the aggregate series will decrease.

Robustness checks are done by running ARFIMA-GARCH $(p, d, q, 1,1)$ models on the monthly data. The findings, displayed in Table 4, are similar with wider standard error bands and more unstable postregime switch estimates. Both are likely due to the shorter sample period during inflation targeting. We also run similar regressions on annualized inflation data, displayed in Table 5. These findings are also similar but display more sign of spurious breaks during the $\mathrm{CZ}$ method. Such a result could possibly mean that the Bai and Perron (1998) methodology performs worse with a larger degree of moving average processes in the data.

Next, we aim to verify that the changes in inflation persistence are indeed caused by the changes in the distribution of expectations. For this purpose, we examine the persistence level in inflation expectations to see if they mimic that of the persistence in actual inflation process. Our theory shows that the persistence in actual inflation is the result of the persistence in inflation expectations, and hence, not finding similar dynamics in the expectations would weaken our hypothesis and favor other causes of persistence changes in inflation. We proxy for inflation expectations using the difference between the nominal and the inflation indexed bond rates from UK and Australia. ${ }^{23}$ The fractional root estimates in Table 6 (again on the demeaned data using the $\mathrm{CZ}$ method) show weak support for our theory. Although the point estimates are very similar to the values in Table 3 and seem to fall with the adoption of IT, the high standard errors (likely due to shorter time periods and high moving average nature of the annual interest rate data) support only marginal levels of significance. Despite this weaker evidence with shorter data, our study still offers an alternative

\footnotetext{
21 Granger and Hyung (1999) show that for simulated nonstationary data after allowing for structural breaks the estimated parameter $d$ only provides evidence of possible spurious break points when it is less than zero.

22 Since the fractional root represents the long run cycles in inflation, one would not expect the results to change in small break date adjustments.

${ }^{23}$ The series start in 1985 for both countries. We cannot use the same proxy for Canada since their inflation indexed bonds start in 1991, just around the time of their IT adoption.
} 
Table 6

Estimates for long memory parameter in inflation expectations (from inflation indexed bonds) before and after regime switch to inflation targeting.

\begin{tabular}{llcc}
\hline & MLE & Switch date \\
\cline { 2 - 3 } & Pre-targeting & Post-targeting & \\
\cline { 2 - 4 } & Coefficient (std.) & Coefficient (std.) & $1993 \mathrm{Q} 2$ \\
\hline Australia & $0.25^{*}(0.15)$ & $0.06(0.17)$ & $1992 \mathrm{Q} 4$ \\
\hline
\end{tabular}

Notes: * represents $90 \%$ significance level. The proxy of inflation expectation used in the regression is the nominal bond rate minus the real rate of inflation indexed bonds. The sample is from 1985M1 for UK and 1985M7 for Australia.

explanation, heterogeneous inflation expectations, for the evidence of long memory process in inflation series.

\section{Conclusion}

The success of inflation targeting is very much dependent on how it reduces the heterogeneity in the public's inflation expectations and concentrates them around the target announcement. Due to insufficient data, the evaluation of this success has been empirically carried out using observable variables like output and various derivatives of inflation. Our study remedies this deficiency by showing a link between the distribution of inflation expectations and inflation persistence. The relation implies that as inflation expectations are moderated (declines in mean and heterogeneity), the (long memory) persistence of actual inflation process should diminish. In empirical tests utilizing eight countries, we show that the inflation persistence levels drop with the adoption of IT.

We realize that the decline in expectations heterogeneity is a sufficient but not a necessary condition for the decline in persistence. However, unavailability of expectations data prohibits any irrefutable analysis of IT's effectiveness on inflation expectations. Therefore, in the search for additional support of our theory, we use a proxy for inflation expectations (only for two countries, again due to insufficient data) to see if the dynamics of inflation expectations resemble that of inflation itself. This estimation shows that the time series properties of expectation proxy resemble the one in actual inflation, supporting IT's effectiveness in reducing the inertia in inflation expectations via their level and heterogeneity.

One can also argue that "the great moderation" and "moderate shocks" led to lower inflation and inflation persistence levels. One should note at this point that our study does not claim that IT is the primary reason for the decline in the persistence of inflation, but the theoretical model shows that increasing credibility of the central banks will also lead to this outcome. Using just inflation targeting countries in the analysis aims to evaluate whether IT, as intended, helped these central banks achieve credibility. For non-targeting countries, the model could offer a more solid explanation to the reduction in persistence than "moderate shocks".

As a byproduct of our study, we are also able to provide (and test) an alternative explanation as to why long memory exists in inflation. The current justifications are persistence in money supply, aggregation of heterogeneous firm production, and the aggregation of individual prices into a price index. The decline in the memory length of inflation that closely follows the adoption of IT provides support to our theory on the impact of IT on expectations heterogeneity than the other explanations of long memory in inflation.

\section{Acknowledgements}

I thank the Scientific and Technical Research Council of Turkey for the research support under the grant SOBAG-105K118. I am also grateful to I. Babetskii, M. Binder, R. Gürkaynak, K. Hasker, R. Horvath, E. Kocenda, A. Kutan, C. Saglam, and S. Sayek for their valuable comments. All remaining errors are mine. 


\section{Appendix I. Derivation of the analytical relation between the mean and variance of $\alpha_{i}$ and the fractional root for Zaffaroni's (2004) semi-parametric distribution}

Zaffaroni (2004) uses a more general semi-parametric distribution to illustrate how cross-sectional aggregation can lead to long memory in the aggregate series. In a model similar to Granger's

$$
x_{i t}=\alpha_{i} x_{i t-1}+u_{t}+\varepsilon_{i t}
$$

He divides the disturbance term into common $\left(u_{t}\right)$ and idiosyncratic $\left(\epsilon_{i t}\right)$ shocks. Using a family of continuous distributions $\beta$

$$
\beta(\alpha, b) \sim C_{b}(1-\alpha)^{b}
$$

where $\alpha \in[0,1), b \in(-1, \infty)$, and $C_{b}$ is an appropriate positive constant, he displays that aggregation will lead to long memory models depending on the density of the distribution of $\alpha_{i}$ around unity. As $b$ approaches -1 , this density will become greater, resulting in stronger persistence. At negative values of $b$, the aggregation of the idiosyncratic or the common components will produce the degrees of differencing, $d=(1-b) / 2$ or $d=-b$, respectively.

Deriving the mean of $\alpha$ for the distribution suggested by Zaffaroni (2004), we find that

$$
\mu_{\alpha}=\frac{C}{(b+1)(b+2)}
$$

for $b \neq-1$. Since $b$ is inversely related to $d$, persistence increases with higher means. As the noncentral moments of their distribution are recurrent $\left(\mu_{n}=[n C /(1+b)(1+n+b)] \mu_{n-1}\right)$, the variance is $\sigma_{\alpha}^{2}=\mu C /(b+2)(b+3)$, and $d$ is also positively related to variance of $\alpha_{i}$. Like Granger, not allowing $\alpha_{i}$ to vary or approach to 1 (by pushing $b$ away from -1 toward positive values) will lead to an exponentially decaying autocovariance function, which is a property of short memory models.

\section{Appendix II. Monte Carlo simulations checking fractional root estimates with varying pre and post-regime sample size lengths}

\section{Table A1}

Monte Carlo simulation for small sample properties of NLS.

\begin{tabular}{lllllll}
\hline$d$ & $\begin{array}{l}\text { Mean } \\
\text { (full sample) }\end{array}$ & $\begin{array}{l}\text { Std. Dev. } \\
\text { (full sample) }\end{array}$ & $\begin{array}{l}\text { Mean } \\
\text { (pre-target) }\end{array}$ & $\begin{array}{l}\text { Std. Dev. } \\
\text { (pre-target) }\end{array}$ & $\begin{array}{l}\text { Mean } \\
\text { (post-target) }\end{array}$ & $\begin{array}{l}\text { Std. Dev. } \\
\text { (post-target) }\end{array}$ \\
\hline 0 & -0.01 & 0.04 & -0.01 & 0.04 & -0.02 & 0.10 \\
0.1 & 0.09 & 0.04 & 0.09 & 0.04 & 0.09 & 0.10 \\
0.2 & 0.19 & 0.04 & 0.19 & 0.04 & 0.19 & 0.11 \\
0.3 & 0.29 & 0.04 & 0.29 & 0.04 & 0.30 & 0.10 \\
0.4 & 0.40 & 0.04 & 0.39 & 0.04 & 0.41 & 0.11 \\
0.5 & 0.50 & 0.04 & 0.50 & 0.04 & 0.53 & 0.10 \\
0.6 & 0.60 & 0.04 & 0.60 & 0.04 & 0.64 & 0.11 \\
0.7 & 0.71 & 0.04 & 0.70 & 0.04 & 0.76 & 0.11 \\
0.8 & 0.81 & 0.04 & 0.81 & 0.04 & 0.88 & 0.11 \\
0.9 & 0.91 & 0.04 & 0.91 & 0.04 & 0.97 & 0.09 \\
1.0 & 1.00 & 0.03 & 0.99 & 0.03 & 1.03 & 0.07 \\
\hline
\end{tabular}

Notes: sample of 550 is split into 400 for the 1 st part and 150 for the 2 nd. Results are from 3000 iterations. ARFIMA model (0, $d$, 0 ) is chosen for ease of display.

\section{References}

Abadir, K.M., Talmain, G., 2002. Aggregation, persistence and volatility in a macromodel. Review of Economic Studies 69, 749-779. Amato, J.D., Gerlach, S., 2002. Inflation targeting in emerging market and transition economies: lessons after a decade. European Economic Review 46, 781-790.

Andersen, T.G., Bollerslev, T., 1997. Heterogeneous information arrivals and returns volatility dynamics: uncovering the long run in high frequency returns. Journal of Finance 52, 975-1005. 
Bai, J., Perron, P., 1998. Estimating and testing linear models with multiple structural changes. Econometrica 66, 47-78.

Baillie, R.T., 1996. Long memory processes and fractional integration in econometrics. Journal of Econometrics 73, 5-59.

Baillie, R.T., Chung, C., Tieslau, M.A., 1996. Analyzing inflation by the fractionally integrated ARFIMA-GARCH model. Journal of Applied Econometrics 11, 23-40.

Ball, L., Sheridan, N., 2005. Does inflation targeting matter? In: Bernanke, B.S., Woodford, M. (Eds.), The Inflation-Targeting Debate. University of Chicago Press.

Bernanke, B.S., Laubach, T., Mishkin, F., Posen, A.S., 1999. Inflation Targeting: Lessons from the International Experience. Princeton University Press, Princeton, NJ.

Bernanke, B.S., Mishkin, F., 1997. Inflation targeting: a new framework for monetary policy? Journal of Economic Perspectives 11 , 97-116.

Chambers, M., 1998. Long memory and aggregation in macroeconomic time series. International Economic Review 39, $1053-1072$.

Choi, K., Zivot, E., 2007. Long memory and structural changes in the forward discount: An empirical investigation. Journal of International Money and Finance 26 (3), pp 342-363.

Corbo, V., Landerretche, O., Schmidt-Hebbel, K., 2001. Assessing Inflation Targeting After a Decade of World Experience. Mimeo, Central Bank of Chile, Santiago.

Crettez, B., Michel, P., 1992. Economically rational expectations equilibrium. Economics Letters 40, 203-206.

Cukierman, A., 1992. Central Bank Strategy, Credibility and Independence. MIT Press, Cambridge, MA.

Demertzis, M., Viegi, N., 2007. Inflation Targeting - a Framework for Communication. DNB Working Papers 149. Netherlands Central Bank, Research Department.

Demir, B., Yigit, T.M., 2008. Announcements and credibility under inflation targeting. Economics Letters 100 (2), $249-253$.

Diebold, F.X., Inoue, A., 2001. Long memory and regime switching. Journal of Econometrics 105, 131-159.

Evans, M., Wachtel, P., 1993. Inflation regimes and the sources of inflation uncertainty. Journal of Money, Credit, and Banking 25 , 475-511.

Evans, G.W., Honkapohja, S., 2001. Learning and Expectations in Macroeconomics. Princeton University Press, Princeton, NJ.

Evans, G.W., Honkapohja, S., Marimon, R., 2001. Convergence in monetary inflation models with heterogeneous learning rules. Macroeconomic Dynamics 5 (1), 1-31.

Faust, J., Henderson, D.W., 2004. Is inflation targeting best-practice monetary policy? Federal Reserve Bank of Saint Louis Review.

Figlewski, S., Wachtel, P., 1981. The formation of inflationary expectations. Review of Economics and Statistics 25, 475-511.

Granger, C.W.J., 1980. Long memory relationships and the aggregation of dynamic models. Journal of Econometrics 14, $227-238$.

Granger, C.W.J., Hyung, N., 1999. Occasional structural breaks and long memory. UCSD Discussion Paper 99-14.

Granger, C.W.J., Joyeux, R., 1980. An introduction to long-memory time series models and fractional differencing. Journal of Time series Analysis 1 (1), 15-29.

Hassler, U., Wolters, J., 1995. Long memory in inflation rates: international evidence. Journal of Business and Economic Statistics $13,37-45$.

Johnson, D., 2002. The effect of inflation targeting on the behavior of expected inflation: evidence from an 11 country panel. Journal of Monetary Economics 49 (8), 1521-1538.

Johnson, D., 2003. The effect of inflation targets on the level of expected inflation in five countries. Review of Economics and Statistics 85 (4), 1076-1081.

Kuttner, K.N., Posen, A.S., 2001. Beyond bipolar: a three-dimensional assessment of monetary frameworks. International Journal of Finance and Economics 6, 369-387.

Leiderman, L., Svensson, L.E.O. (Eds.), 1995. Inflation Targets. Centre for Economic Policy Research, London.

Levin, A.T., Natalucci, F.M., Piger, J.M., 2004. The macroeconomic effects of inflation targeting. Federal Reserve Bank of Saint Louis Review.

Lin, S., Ye, H., 2007. Does inflation targeting really make a difference? Evaluating the treatment effect of inflation targeting in seven industrial countries. Journal of Monetary Economics 54 (8), pp. 2521-2533.

Liu, M., 2000. Modeling long memory in stock market volatility. Journal of Econometrics 99, 139-171.

Mishkin, F.S., Schmidt-Hebbel, K., 2001. One decade of inflation targeting in the world: what do we know and what do we need to know? In: Loayza, N., Soto, R. (Eds.), A Decade of Inflation Targeting in the World. Central Bank of Chile, Santiago, pp. 117-219.

Naish, H.F., 1993. The near optimality of adaptive expectations. Journal of Economic Behavior and Organization $20,3-22$.

Neumann, M.J.M., von Hagen, J., 2002. Does inflation targeting matter? Federal Reserve Bank of Saint Louis Review, 1-22.

Ooms, M., Doornik, J.A., 1998. Estimation, simulation and forecasting for fractional autoregressive integrated moving average models. Discussion paper, Econometric Intitute, Erasmus University Rotterdam, presented at the fourth annual meeting of the Society for Computational Economics. Cambridge, UK.

Ooms, M., Doornik, J., 1999. Inference and Forecasting for Autoregressive Fractional Integrated Moving Average Models, with an Application to US and UK Inflation. Erasmus University of Rotterdam. Working Paper.

Parke, W.R., 1999. What is fractional integration? Review of Economics and Statistics 81, 632-638.

Petursson, T.G., 2004. The Effects of Inflation Targeting on Macroeconomic Performance, SUERF Studies, 2005/5.

Scacciavillani, F., 1994. Long memory processes and chronic inflation. IMF Staff Papers 41, 488-501.

Schaechter, A., Stone, M.R., Zelmer, M., 2000. Adopting Inflation Targeting: Practical Issues for Emerging Economies. IMF Occasional Paper No. 202. IMF.

Siklos, P.L., 1999. Inflation target design: changing inflation performance and persistence in industrial countries. Federal Reserve Bank of Saint Louis Review.

Sowell, F.B., 1992. Modeling long-run behavior with fractional ARIMA model. Journal of Monetary Economics 29, $277-302$.

Walsh, C.E., 1999. Announcements, inflation targeting and central bank incentives. Economica 66, 255-269.

Woodford, M., 2004. Inflation targeting and optimal monetary policy. Federal Reserve Bank of Saint Louis Review.

Zaffaroni, P., 2004. Contemporaneous aggregation of linear dynamic models in large economies. Journal of Econometrics 120 , 75-102.

Zarnowitz, V., 1985. Rational expectations and macroeconomic forecasts. Journal of Business and Economic Statistics 3, $293-311$. 